\title{
Evaluation of a more ventral starting point for thoracic pedicle screws: higher maximal insertional arc and more medial and safer screw angulation
}

\author{
*James D. Lin, MD, MS, ${ }^{1}$ Chao Wei, MD, ${ }^{2}$ Jamal N. Shillingford, MD, ${ }^{1}$ Eduardo C. Beauchamp, MD, ${ }^{1}$ \\ Lee A. Tan, MD, ${ }^{3}$ Yongjung J. Kim, ${ }^{1}$ Ronald A. Lehman Jr., MD, ${ }^{1}$ and Lawrence G. Lenke, MD ${ }^{1}$ \\ 1Department of Orthopedic Surgery, Columbia University Medical Center, The Spine Hospital at NewYork-Presbyterian/Allen, \\ New York, New York; ${ }^{2}$ Department of Spine Surgery, The First Affiliated Hospital of Fujian Medical University, Fuzhou, Fujian, \\ China P.R.; and ${ }^{3}$ Department of Neurological Surgery, UCSF Medical Center, San Francisco, California
}

\begin{abstract}
OBJECTIVE To demonstrate that a more ventral starting point for thoracic pedicle screw insertion, produced by aggressively removing the dorsal transverse process bone down to the superior articular facet (SAF), results in a larger margin for error and more medial screw angulation compared to the traditional dorsal starting point (DSP). The margin for error will be quantified by the maximal insertional $\operatorname{arc}(\mathrm{MIA})$.
\end{abstract}

METHODS The study population included 10 consecutive operative patients with adult idiopathic scoliosis who underwent primary surgery. All measurements were performed using 3D visualization software by an attending spine surgeon. The screw starting points were $2 \mathrm{~mm}$ lateral to the midline of the SAF in the mediolateral direction and in the center of the pedicle in the cephalocaudal direction. The DSP was on the dorsal cortex. The ventral starting point (VSP) was at the depth of the SAF. Measurements included distance to the pedicle isthmus, MIA, and screw trajectories.

RESULTS Ten patients and 110 vertebral levels (T1-11) were measured. The patients' average age was 41.4 years (range 18-64 years). The pedicle isthmus was largest at T1 $(4.04 \pm 1.09 \mathrm{~mm})$, and smallest at T5 $(1.05 \pm 0.93 \mathrm{~mm})$. The distance to the pedicle isthmus was $7.47 \mathrm{~mm}$ for the VSP and $11.92 \mathrm{~mm}$ for the DSP $(p<0.001)$. The MIA was $15.3^{\circ}$ for the VSP and $10.1^{\circ}$ for the DSP $(p<0.001)$. Screw angulation was $21.7^{\circ}$ for the VSP and $16.8^{\circ}$ for the DSP $(p<0.001)$.

CONCLUSIONS A more ventral starting point for thoracic pedicle screws results in increased MIA and more medial screw angulation. The increased MIA represents an increased tolerance for error that should improve the safety of pedicle screw placement. More medial screw angulation allows improved triangulation of pedicle screws.

https://thejns.org/doi/abs/10.3171/2018.8.SPINE18175

KEYWORDS thoracic; pedicle screw; maximal insertional arc; safety; freehand technique

$\mathrm{P}$ EDICLE screw fixation has become the most widely used method in modern spinal instrumentation for the thoracolumbar spine. ${ }^{2,4,17}$ Its advantages include superior pullout strength and improved 3D control of the spinal column compared to other fixation methods. The freehand technique of thoracic pedicle screw insertion without fluoroscopic or navigation guidance has been shown to be accurate and safe. ${ }^{12,13}$ Several large published studies have demonstrated a low incidence of screw malposition and an even lower incidence of neurovascular complications associated with the freehand technique., ${ }^{4,10,16,19}$
Nonetheless, freehand thoracic pedicle screw placement can be technically challenging due to the small pedicle dimensions and the narrow margin for error, given the proximity of neurovascular structures. ${ }^{18,20,21}$ In the setting of spinal deformity, significant side-to-side asymmetry and the presence of abnormal pedicles can make instrumentation even more difficult. ${ }^{3,25}$ Spine surgeons who utilize the freehand technique must have a solid understanding of the bony anatomy for each individual patient and be constantly vigilant about safety in order to avoid potential complications.

ABBREVIATIONS DSP = dorsal starting point; MIA = maximal insertional arc; $\mathrm{SAF}=$ superior articular facet; $\mathrm{VSP}$ = ventral starting point. SUBMITTED February 10, 2018. ACCEPTED August 15, 2018.

INCLUDE WHEN CITING Published online December 14, 2018; DOI: 10.3171/2018.8.SPINE18175.

${ }^{*}$ J.D.L. and C.W. share first authorship of this work. 
The freehand technique for pedicle screw placement was previously described in 2004 by Kim et al., ${ }^{12}$ who emphasized that a "step-wise, consistent, and compulsive manner" results in reliable and safe pedicle screws. The freehand thoracic pedicle screw insertion technique can be summarized in the following steps: 1) meticulous exposure of the dorsal bony surface of the spine; 2) creation of a pilot hole in the dorsal cortex with a high-speed burr; 3) cannulation of the pedicle using a thoracic gearshift with the curved tip directed laterally for the first $15-20 \mathrm{~mm}$ (avoids medial breach into the canal), then rotating $180^{\circ}$ and directing the curved tip medially thereafter (provides a medial trajectory into the vertebral body); 4) palpation for pedicle breaches and pedicle length measurement using a flexible ball tip probe; and 5) tapping, re-palpation with ball tip probe, and insertion of the pedicle screw.

For the past decade, the senior author (L.G.L.) has been placing freehand thoracic pedicle screws with a modification of this technique, which we will refer to as the "ventral starting point" (VSP) technique. Specifically, prior to creating the pilot hole, a large Leksell rongeur is used to aggressively remove the dorsal transverse process bone down to the depth of the superior articular facet (Figs. 1 and 2). This is followed by creating a pilot hole at the appropriate starting point as previously described, and the remaining steps of screw insertion are carried out in the same manner as described by Kim et al. ${ }^{12}$

A more ventral starting point allows the surgeon to start closer to the pedicle entrance, which increases the margin of error and allows for more medial screw angulation. This is especially helpful for placement of juxtapedicular screws, where a more ventral starting point allows the screw to be directed more medially into the vertebral body, ventral to the spinal canal.

This study aims to demonstrate that the VSP technique results in a larger margin for error and a more medial screw angulation compared to the traditional dorsal starting point (DSP) by analyzing the preoperative CT scans of spinal deformity patients. The margin for error is quantified by the maximal insertional arc (MIA), which is defined as the "clinical intraoperative tolerance for accurate screw placement as experienced by surgeon." ${ }^{5}$

\section{Methods}

The research protocol was approved by the Columbia University institutional review board. Ten consecutive adult patients (age $\geq 18$ years) with the diagnosis of idiopathic scoliosis who underwent spinal deformity surgery
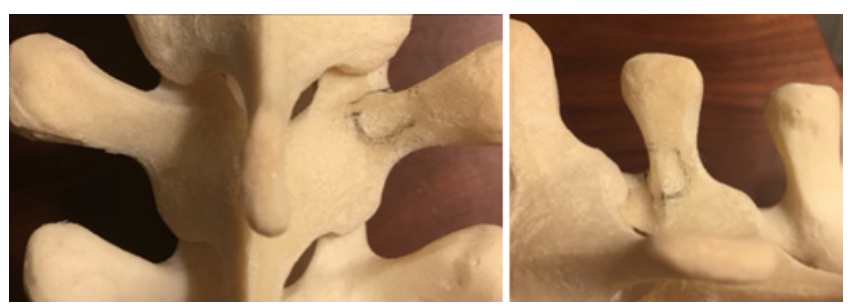

FIG. 1. Sawbones model demonstrating the area of dorsal transverse bone to be removed (circled in black with marking pen) to access the VSP. Figure is available in color online only.
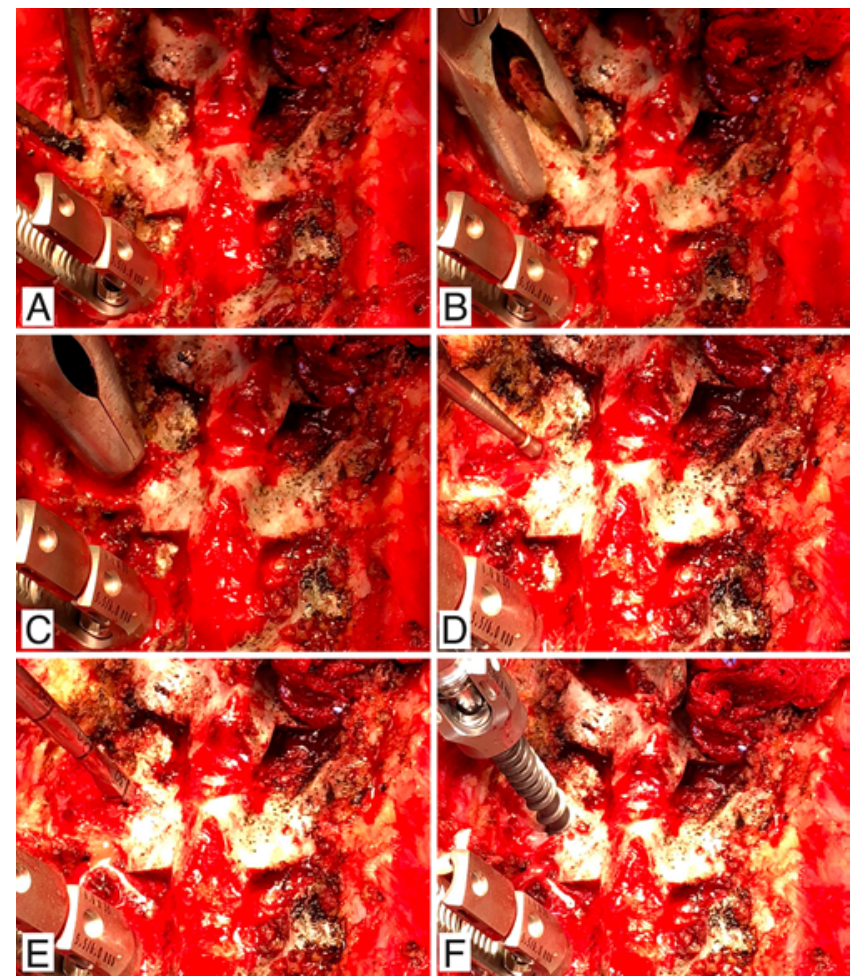

FIG. 2. Intraoperative images demonstrating key steps of freehand pedicle screw insertion using the VSP technique. A: Exposure of dorsal bony landmarks to the tips of the transverse process. B: A large Leksell rongeur is placed with one jaw on the superior articular facet to set the depth of bone removal. C: Removal of dorsal transverse process bone to the depth of the superior articular facet. D: Creation of pilot hole with a matchstick burr. E: Cannulation of the pedicle with a thoracic gearshift probe. F: Insertion of pedicle screw. Figure is available in color online only.

performed by the senior author (L.G.L.) at a single institution were identified. Their preoperative CT images were analyzed, and specific parameters were measured as detailed below.

All measurements were performed using 3D visualization software (VitreaCore version 6.7.6; ViTAL). Measurements were performed bilaterally at each thoracic spinal level from T1 through T11. T12 was excluded because of the transitional nature of this vertebra and lack a true thoracic transverse process. For each level, the axis of the visualization software was recalibrated to orient the vertebral body with proper alignment in all 3 planes.

\section{Pedicle Measurements}

Pedicle isthmus width, defined as the endosteal diameter of the pedicle, was measured at each level. ${ }^{18}$ The endosteal diameter was chosen because we believe that the inner cortical diameter is the critical measurement relevant to pedicle screw instrumentation. ${ }^{9}$

\section{Starting Points}

Transpedicular screw trajectories were measured unless the pedicle isthmus was $<1 \mathrm{~mm}$; in these cases juxtapedicular screw trajectories were measured. For transpedicular screws, the mediolateral position of the starting 

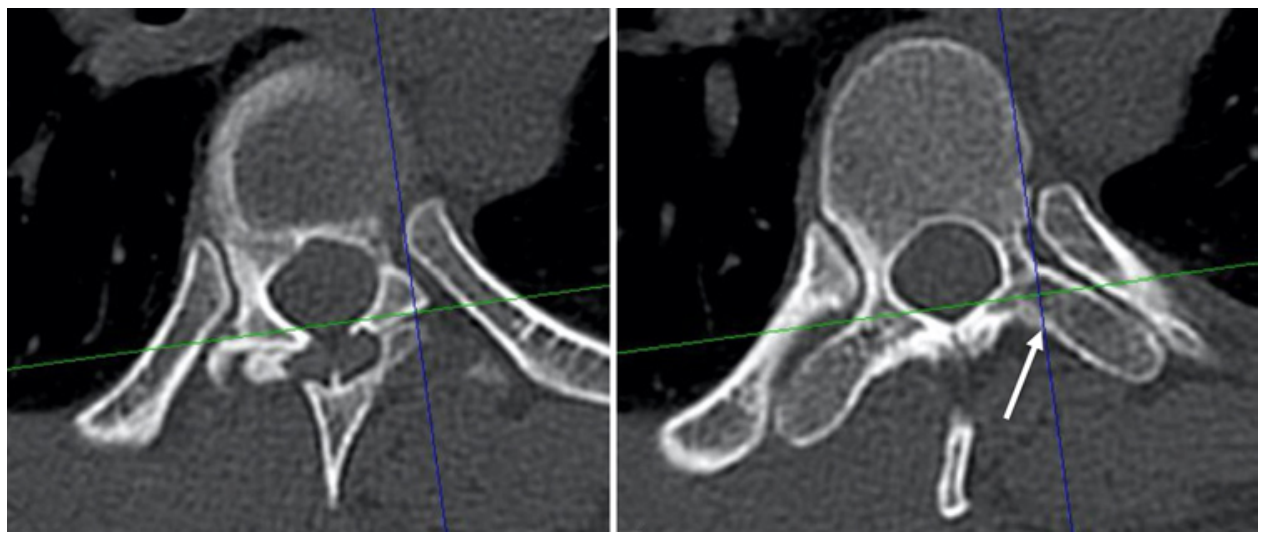

FIG. 3. Determination of starting point on the left pedicle of the T8 vertebra. Left: The mediolateral position of the starting point is $2 \mathrm{~mm}$ lateral to the midline of the SAF. Right: The cephalocaudal position is in the center of the pedicle. The VSP is marked by blue/green crosshairs. The DSP is marked by the tip of the white arrow. Figure is available in color online only.

point was $2 \mathrm{~mm}$ lateral to the midline of the superior articular facet (SAF) ${ }^{15}$ For juxtapedicular screws, the starting point was $1 \mathrm{~mm}$ medial to the lateral aspect of the base of the SAF. The cephalocaudal position of the starting point was chosen to be in the center of the pedicle in the sagittal plane. The dorsal starting point (DSP) was defined as being on the dorsal cortex of the lamina-transverse process junction. The ventral starting point (VSP) was defined as being at the "depth" of the base of the SAF in the dorsalventral axis (Fig. 3). The distances from the DSP and the VSP to the midpoint of the pedicle isthmus were recorded.

\section{Maximal Insertional Arc}

The maximal insertional arc (MIA) is defined as the arc of possible pedicle screw trajectories without pedicle breach from the starting point, subtended by the most medial and lateral possible trajectories. The medial trajectory was limited by the medial pedicle wall. The lateral trajectory was the most lateral trajectory possible with a minimum of $50 \%$ vertebral body purchase (Fig. 4). In juxtapedicular trajectories, the medial trajectory was limited by the lateral pedicle wall, and the lateral trajectory was the most lateral trajectory possible with a minimum of $50 \%$ vertebral body purchase.

\section{Screw Trajectory}

In the sagittal plane, a straightforward screw trajectory was used parallel to the superior endplate. ${ }^{17}$ In the axial plane, screw trajectories were directed toward the midline of the ventral vertebral body cortex, as limited by the confines of the pedicle.

\section{Statistical Analysis}

Distribution of variables is presented as the mean \pm standard deviation. The paired t-test was used to determine clinical significance between the ventral and dorsal starting points. A p value $<0.05$ was considered statistically significant.

\section{Results}

There were 10 patients included in this study, with a total of 110 vertebral levels (T1-11) measured and analyzed. The patients' mean age was 41.4 years (range 18-64 years). Nine patients were female. All patients had the diagnosis of adult idiopathic scoliosis.

\section{Anatomical Characteristics}

The average pedicle isthmus width was $1.9 \mathrm{~mm}$ (range 0-6.1 mm). Pedicle isthmus width was largest at T1, with a mean of $4.04 \pm 1.09 \mathrm{~mm}$, and smallest at T5, with a mean of $1.05 \pm 0.93 \mathrm{~mm}$ (Fig. 5).

\section{Starting Point Analysis}

The VSP was on average $4.45 \mathrm{~mm}$ closer to the pedicle isthmus compared to the DSP, with a mean distance of 7.47 $\pm 1.44 \mathrm{~mm}$ versus $11.92 \pm 2.61 \mathrm{~mm}(\mathrm{p}<0.001)$ to the isthmus. The largest difference in distance between the DSP and VSP occurred at T3, T11, and T2, with mean differences of 5.38, 5.32, and $5.14 \mathrm{~mm}$, respectively. The smallest difference occurred at T1, T7, and T6, with mean differences of 2.52, 3.84, and $4.26 \mathrm{~mm}$, respectively (Fig. 6).

\section{Maximal Insertional Arc}

The mean MIA was $15.3^{\circ} \pm 6.8^{\circ}$ for the VSP and $10.1^{\circ}$

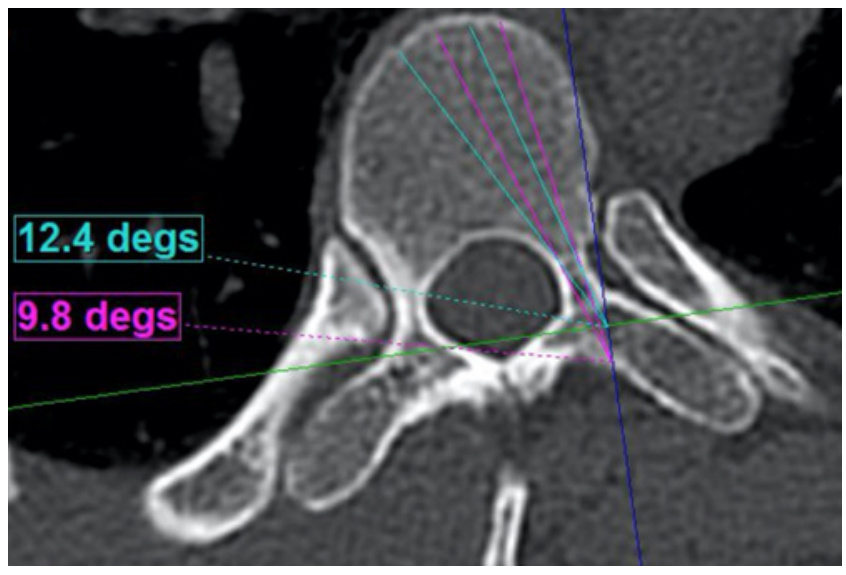

FIG. 4. MIA from VSP (blue) and DSP (pink). degs = degrees. Figure is available in color online only. 


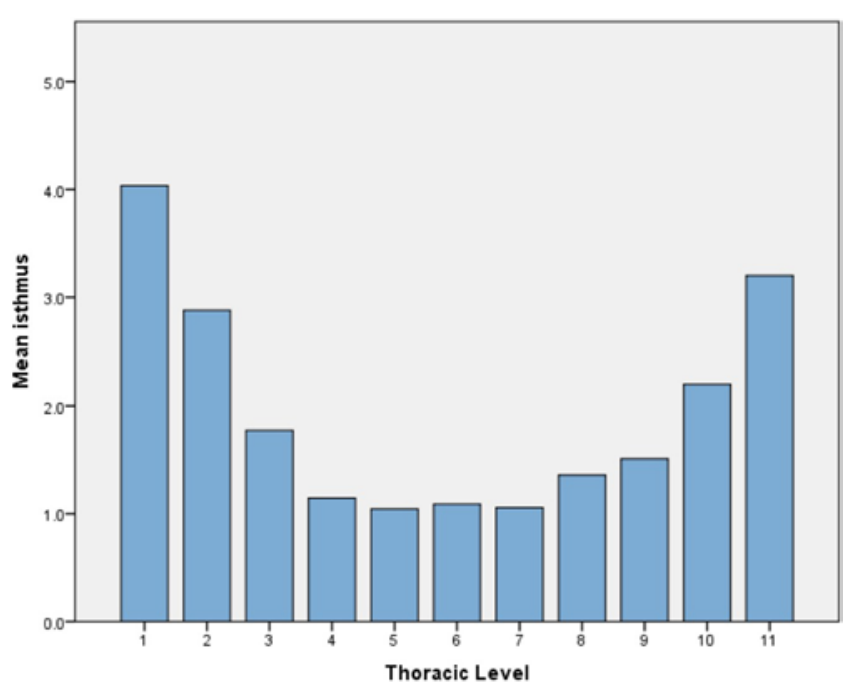

FIG. 5. Mean pedicle isthmus. The y-axis values are mean endosteal diameter measurements in millimeters. Figure is available in color online only.

$\pm 5.1^{\circ}$ for the DSP $(\mathrm{p}<0.001)$. The MIA was greatest at $\mathrm{T} 1$ and smallest at T5 (Fig. 7).

\section{Screw Trajectory and Lengths}

Screw trajectories from VSP had on average $4.97^{\circ}$ more medial angulation compared to trajectories from the DSP. The mean screw angle in the axial plane was $21.7^{\circ} \pm$ $8.6^{\circ}$ for the VSP and $16.8^{\circ} \pm 7.9^{\circ}$ for the DSP $(p<0.001)$ (Fig. 8).

Screw lengths from the VSP were on average $3.37 \mathrm{~mm}$ shorter than screw lengths from the DSP. The mean screw length was $36.2 \pm 4.3 \mathrm{~mm}$ from the VSP and $39.6 \pm 5.0$ $\mathrm{mm}$ from the DSP $(\mathrm{p}<0.001)$. Screw lengths were shortest at T1 $(31.10 \mathrm{~mm}$ ventral, $33.56 \mathrm{~mm}$ dorsal) and increased progressively to T11 (41.23 $\mathrm{mm}$ ventral, $45.42 \mathrm{~mm}$ dorsal).

\section{Juxtapedicular Trajectories}

For levels where juxtapedicular screws were placed (n $=44$ ), the average MIA for the VSP was $14.7^{\circ} \pm 6.1^{\circ}$, and the average MIA for the DSP was $6.3^{\circ} \pm 3.2^{\circ}(\mathrm{p}<0.001)$. The average screw angle for the VSP was $19.5^{\circ} \pm 5.5^{\circ}$, and the average screw angle for the DSP was $12.4^{\circ} \pm 4.6^{\circ}$. The average screw length for the VSP was $36.9 \pm 3.0 \mathrm{~mm}$, and the average screw length for the DSP was $40.7 \pm 4.4 \mathrm{~mm}$.

\section{Discussion}

Freehand thoracic pedicle screw placement has been shown to be a safe and efficient method for spinal instrumentation, with numerous studies demonstrating low rates of neurological complications. , $^{4,12,13,16,19}$ However, freehand screw placement can be challenging due to the small pedicles in close proximity to important neurovascular structures. ${ }^{21,24}$ Most descriptions of the freehand technique follow a series of key steps, including creating a pilot hole in the dorsal cortex at a specified starting point, cannulating the pedicle with a gearshift, and probing the pedicle for potential breaches. ${ }^{8,12,15,19}$ For the past

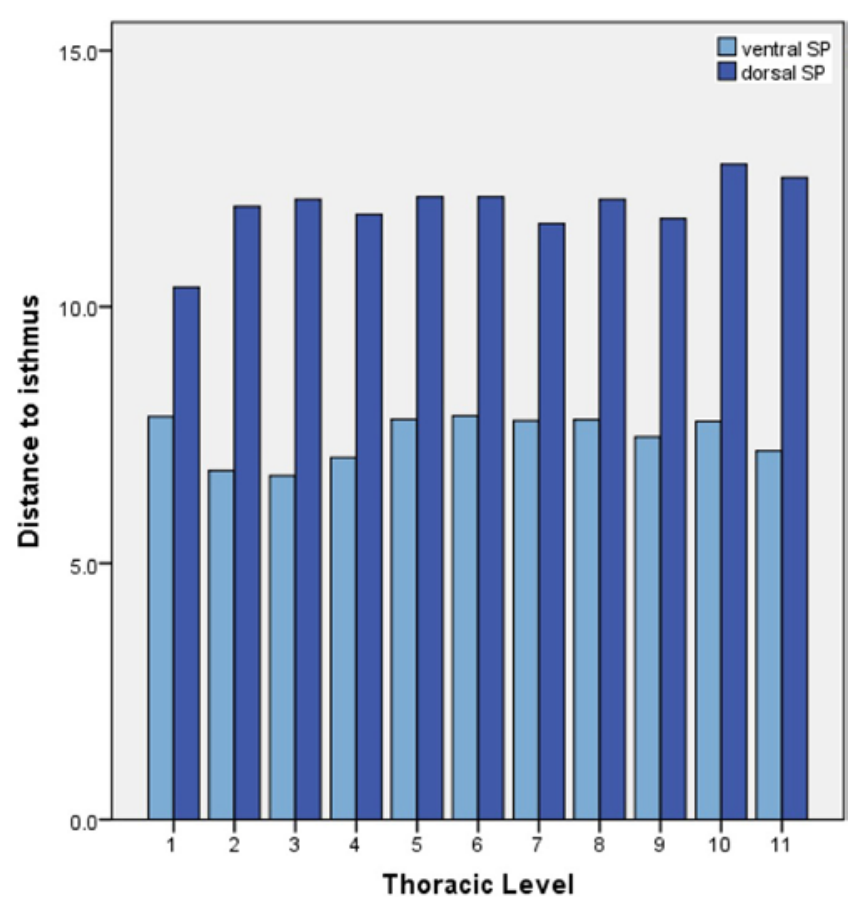

FIG. 6. Distance from starting point to isthmus. The y-axis values are mean distance measurements in millimeters. SP = starting point. Figure is available in color online only.

decade, the senior author has utilized a modified freehand technique with a more ventral starting point. Prior to creating a pilot hole, the dorsal bone at the lamina-transverse process junction is removed with a large rongeur to the depth of the superior articular facet (SAF), creating a flat surface from the SAF to the starting point. This technique has several advantages, namely: 1) creating a starting point closer to pedicle entrance, thereby improving accuracy and safety; 2) allowing more medial angulation of screws for improved triangulation; 3) creating a flat surface on which to start the pilot hole and seat the screw head; and 4) harvesting more autograft bone for arthrodesis.

Maximal insertional arc (MIA) was defined by Dhawan et al. as "the angle formed by the most cephalad and caudad directed lines through a specific start point without cortical perforation of the pedicle and passing at least $50 \%$ across the vertebral body." 5 They used this measure to compare the tolerance for accurate screw placement in the sagittal plane between the straightforward and anatomical trajectories and showed that the anatomical trajectory had a mean increase in MIA of $4.4^{\circ}$ across the thoracic spine. In the present study, we have applied the MIA measure to the axial plane and shown that a more ventral starting point results in a higher MIA.

In our study, we found that the VSP generated a 51\% increase in MIA compared to the DSP. The mean MIA values for the ventral and dorsal starting points were $15.3^{\circ}$ and $10.1^{\circ}$, respectively. Screw trajectories were also more medial with the VSP, reflecting an increased ability to medialize the screw trajectory for screw triangulation. The mean screw angle was $21.7^{\circ}$ for the VSP and $16.8^{\circ}$ for 


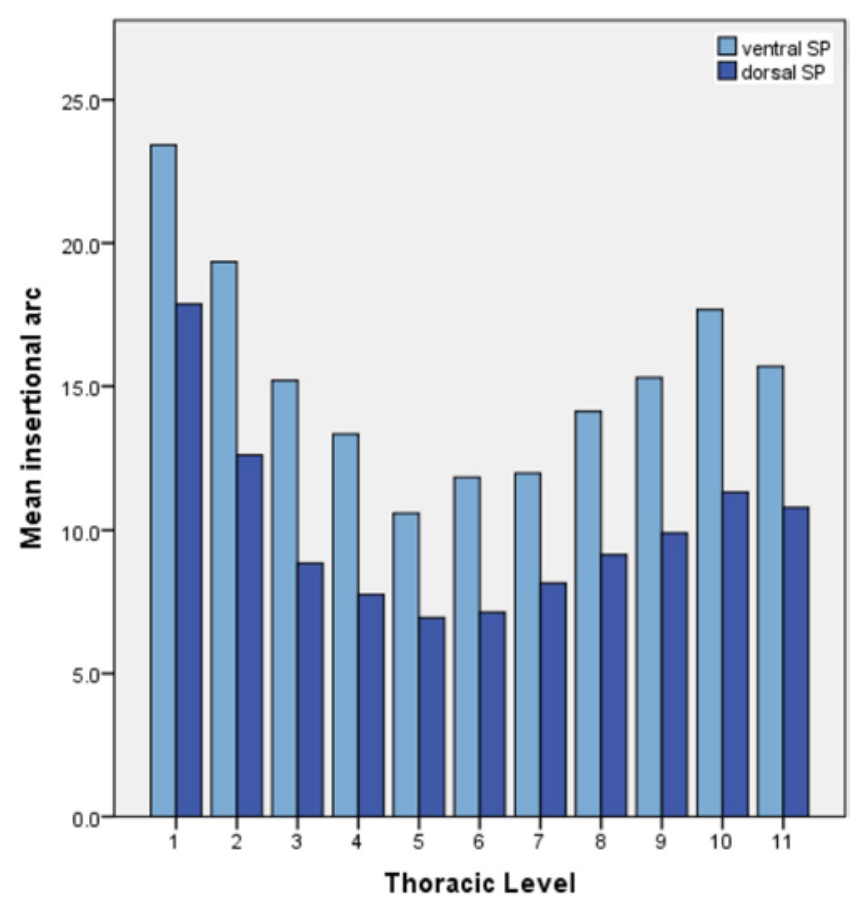

FIG. 7. Maximal insertional arc. The y-axis values are mean MIA measurements in degrees. Figure is available in color online only.

the DSP. The differences between the VSP and DSP were more pronounced in juxtapedicular trajectories, where the mean MIA for the VSP was $14.7^{\circ}$, and the mean MIA for the DSP was $6.3^{\circ}$, reflecting a $233 \%$ increase for the VSP.

Several intraoperative techniques have been described to improve the safety of thoracic pedicle screw placement. Di Silvestre et al. ${ }^{6}$ reported their results using a "mini-laminotomy" technique to palpate the borders of the pedicle prior to screw insertion. They found that 18 of 1035 screws were misplaced, but with no neurological complications. However, incidental durotomies occurred in 15 patients (13\%), which appears to be a higher frequency than in our anecdotal experience with freehand pedicle screw insertion. Lehman et al. ${ }^{15}$ described the "ventral lamina," which is the confluence of the roof of the spinal canal and the medial pedicle wall, as a structure that can be palpated intraoperatively to help funnel the pedicle probe into the pedicle. ${ }^{1}$ Watanabe et al. ${ }^{26}$ showed that the use of a flexible ball tip probe to enter the pedicle, instead of a traditional thoracic pedicle gearshift, resulted in a decrease in pedicle breaches. While the flexibility of the probe and the blunt nature of the ball tip probe should protect against pedicle wall breaches, Watanabe et al. acknowledge that this technique may not work for pedicles with cortical or small cancellous channels. Gaines described the "funnel technique" in which a 1-cm diameter of cortical bone is removed and curettes are used to remove the cancellous bone overlying the pedicle entrance until cortical walls of the pedicle are directly visualized. ${ }^{9}$ While the funnel technique is similar in concept to the VSP technique, it requires several additional steps per screw, which we feel are time-consuming and unnecessary. We believe the VSP technique is an efficient technique that is applicable to all

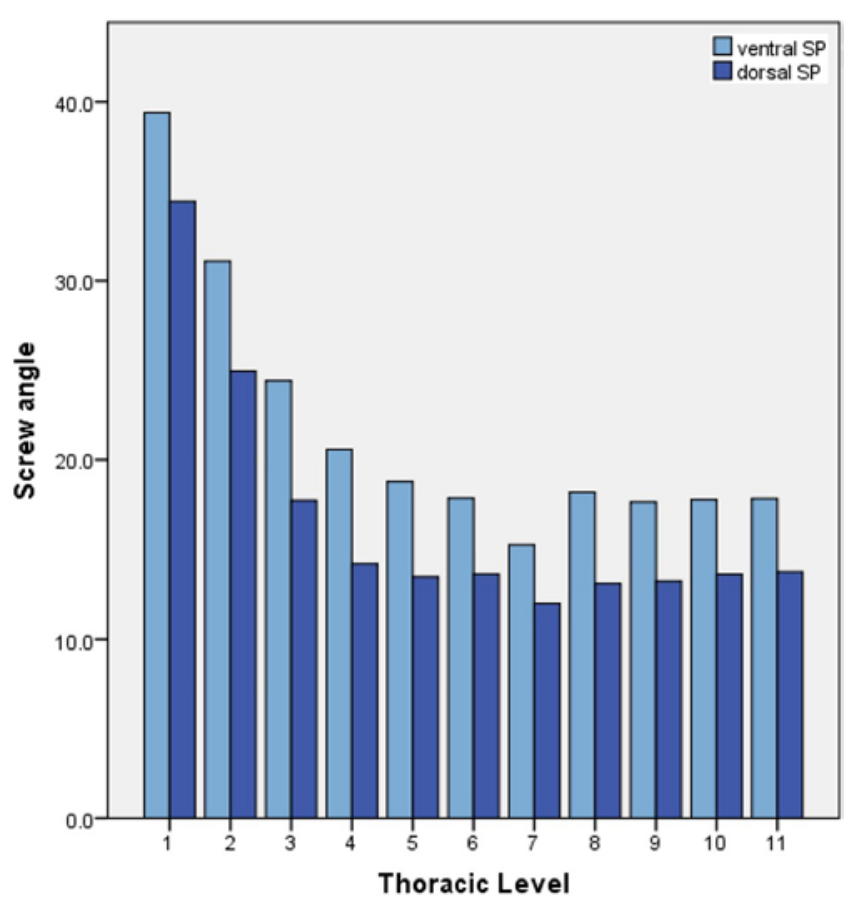

FIG. 8. Screw angles. The y-axis values are mean angle measurements in degrees. Figure is available in color online only.

pedicle types and can improve the safety of freehand pedicle screw placement.

The morphology of thoracic pedicles has been studied through numerous cadaveric and imaging studies, in both normal spines and spinal deformity patients. The fourth through sixth thoracic vertebrae (T4-6) tend to have the narrowest pedicles in the axial plane, with mean isthmus measurements ranging from 2.5 to $4.5 \mathrm{~mm} .14,18,27$ The trend in pedicle isthmus sizes that we report in this study is similar, with the smallest mean isthmus measurement of 1.05 $\mathrm{mm}$ at T5. The smaller isthmus sizes in this study may reflect our study population of idiopathic scoliosis patients and the fact that we measured the endosteal diameter of the pedicle. We believe that the inner cortical diameter is the critical measurement relevant to pedicle screw instrumentation. ${ }^{9}$ Watanabe et al. ${ }^{25}$ classified pedicles from A to $\mathrm{D}$, based on intraoperative feel with the pedicle probe, to describe the osseous anatomy encountered by the pedicle probe. In a CT-based study assessing abnormal pedicles in patients with adult idiopathic scoliosis, Sarwahi et al. ${ }^{22}$ proposed radiographic criteria for the Watanabe classification as follows: type A, cancellous channel $>4 \mathrm{~mm}$; type $\mathrm{B}$, cancellous channel 2-4 $\mathrm{mm}$; type $\mathrm{C}$, cortical channel $\geq 2 \mathrm{~mm}$; type $\mathrm{D}$, cortical channel $<2 \mathrm{~mm}$. However, pedicle dimensions were measured from outer cortex to outer cortex. Since we measured endosteal isthmus width, we defined isthmus diameter $<1 \mathrm{~mm}$ to be a type $\mathrm{D}$ pedicle requiring a juxtapedicular trajectory. This reflects our clinical practice, where a "baby" thoracic pedicle probe with a 1-mm tip is used to navigate tight pedicles.

The distance from the dorsal cortex to the pedicle isthmus has been reported in the literature to range from 10.7 to $13.6 \mathrm{~mm}$ depending on the level in the thoracic spine. ${ }^{20}$ 
During freehand thoracic pedicle screw placement, this is the basis for keeping the pedicle gearshift turned laterally for the first $15 \mathrm{~mm}$, followed by turning medially to enter the vertebral body. We found the distance from the DSP to the isthmus to be $11.92 \mathrm{~mm}$, which is consistent with the literature, while the distance from the VSP to the isthmus was over $4 \mathrm{~mm}$ closer at $7.47 \mathrm{~mm}$.

The findings of this study should be interpreted in light of several limitations. This was a CT-based study looking at idealized pedicle screw trajectories and theoretical insertional arcs. Screw widths were not taken into account due to a limitation in our 3D visualization software. However, in contrast to other radiographic studies, our study included only operative adult idiopathic scoliosis patients to capture the high number of abnormal pedicles across the thoracic spine. We believe this makes the results of this study more generalizable to spinal deformity patients. The nature of CT-based measurements allows precise measurement of angles and trajectories in operative deformity patients, which is not possible in cadaver-based studies. While the results of this study show that the VSP should increase the tolerance for error and allow more medial screw trajectories, the biomechanical implications of removing the dorsal cortex is unclear. Some studies have shown that screw hubbing decreases pullout strength. ${ }^{11,15}$ Other authors argue that screw triangulation is biomechanically advantageous. ${ }^{1,19}$ Further biomechanical studies need to be performed to clarify this issue. In practice, we do not use the VSP technique on the cephalad level of a spinal deformity construct mainly because only the caudal half of the transverse process is exposed and the superior articular facet is not visualized. This may mitigate any potential biomechanical effects that the VSP technique would have in an area where proximal junctional kyphosis is a concern. While further clinical studies are necessary to prove the clinical accuracy and safety benefits of the VSP technique, we have recently published a paper in which VSP techniques were utilized in a series of highly complex spinal deformity cases, showing $96.3 \%$ of 513 pedicle screws placed in an acceptable position based on $\mathrm{O}$-arm imaging. ${ }^{23}$ Ultimately, the increased potential for safety that is afforded by the larger MIA has made this a key step in our freehand technique.

\section{Conclusions}

In conclusion, a more ventral starting point for thoracic pedicle screw placement increases the MIA and allows for more medial screw angulation. Starting closer to the pedicle entrance increases the tolerance for error and can potentially further improve the safety of freehand thoracic pedicle screw placement. Further studies are necessary to evaluate the biomechanical effects of a more ventral starting point.

\section{References}

1. Barber JW, Boden SD, Ganey T, Hutton WC: Biomechanical study of lumbar pedicle screws: does convergence affect axial pullout strength? J Spinal Disord 11:215-220, 1998

2. Cho W, Cho SK, Wu C: The biomechanics of pedicle screwbased instrumentation. J Bone Joint Surg Br 92:1061-1065, 2010
3. Davis CM, Grant CA, Pearcy MJ, Askin GN, Labrom RD, Izatt MT, et al: Is there asymmetry between the concave and convex pedicles in adolescent idiopathic scoliosis? A CT investigation. Clin Orthop Relat Res 475:884-893, 2017

4. Dede O, Ward WT, Bosch P, Bowles AJ, Roach JW: Using the freehand pedicle screw placement technique in adolescent idiopathic scoliosis surgery: what is the incidence of neurological symptoms secondary to misplaced screws? Spine (Phila Pa 1976) 39:286-290, 2014

5. Dhawan A, Klemme WR, Polly DW Jr: Thoracic pedicle screws: comparison of start points and trajectories. Spine (Phila Pa 1976) 33:2675-2681, 2008

6. Di Silvestre M, Parisini P, Lolli F, Bakaloudis G: Complications of thoracic pedicle screws in scoliosis treatment. Spine (Phila Pa 1976) 32:1655-1661, 2007

7. Diab M, Smith AR, Kuklo TR: Neural complications in the surgical treatment of adolescent idiopathic scoliosis. Spine (Phila Pa 1976) 32:2759-2763, 2007

8. Fennell VS, Palejwala S, Skoch J, Stidd DA, Baaj AA: Freehand thoracic pedicle screw technique using a uniform entry point and sagittal trajectory for all levels: preliminary clinical experience. J Neurosurg Spine 21:778-784, 2014

9. Gaines RW Jr: The use of pedicle-screw internal fixation for the operative treatment of spinal disorders. J Bone Joint Surg Am 82-A:1458-1476, 2000

10. Gautschi OP, Schatlo B, Schaller K, Tessitore E: Clinically relevant complications related to pedicle screw placement in thoracolumbar surgery and their management: a literature review of 35,630 pedicle screws. Neurosurg Focus 31(4):E8, 2011

11. Kang DG, Lehman RA Jr, Bevevino AJ, Gaume RE, Purcell RL, Dmitriev AE, et al: Pedicle screw "hubbing" in the immature thoracic spine: a biomechanical and micro-computed tomography evaluation. J Pediatr Orthop 34:703-709, 2014

12. Kim YJ, Lenke LG, Bridwell KH, Cho YS, Riew KD: Free hand pedicle screw placement in the thoracic spine: is it safe? Spine (Phila Pa 1976) 29:333-342, 2004

13. Kim YW, Lenke LG, Kim YJ, Bridwell KH, Kim YB, Watanabe K, et al: Free-hand pedicle screw placement during revision spinal surgery: analysis of 552 screws. Spine (Phila Pa 1976) 33:1141-1148, 2008

14. Kretzer RM, Chaput C, Sciubba DM, Garonzik IM, Jallo GI, McAfee PC, et al: A computed tomography-based morphometric study of thoracic pedicle anatomy in a random United States trauma population. J Neurosurg Spine 14:235-243, 2011

15. Lehman RA Jr, Kang DG, Lenke LG, Gaume RE, Paik H: The ventral lamina and superior facet rule: a morphometric analysis for an ideal thoracic pedicle screw starting point. Spine J 14:137-144, 2014

16. Lehman RA Jr, Lenke LG, Keeler KA, Kim YJ, Cheh G: Computed tomography evaluation of pedicle screws placed in the pediatric deformed spine over an 8 -year period. Spine (Phila Pa 1976) 32:2679-2684, 2007

17. Lehman RA Jr, Polly DW Jr, Kuklo TR, Cunningham B, Kirk KL, Belmont PJ Jr: Straight-forward versus anatomic trajectory technique of thoracic pedicle screw fixation: a biomechanical analysis. Spine (Phila Pa 1976) 28:2058-2065, 2003

18. Liljenqvist UR, Allkemper T, Hackenberg L, Link TM, Steinbeck J, Halm HFH: Analysis of vertebral morphology in idiopathic scoliosis with use of magnetic resonance imaging and multiplanar reconstruction. J Bone Joint Surg Am 84A:359-368, 2002

19. Parker SL, McGirt MJ, Farber SH, Amin AG, Rick AM, Suk I, et al: Accuracy of free-hand pedicle screws in the thoracic and lumbar spine: analysis of 6816 consecutive screws. Neurosurgery 68:170-178, 2011

20. Rampersaud YR, Simon DA, Foley KT: Accuracy require- 
ments for image-guided spinal pedicle screw placement. Spine (Phila Pa 1976) 26:352-359, 2001

21. Şarlak AY, Buluç L, Sarisoy HT, Memişoğlu K, Tosun B: Placement of pedicle screws in thoracic idiopathic scoliosis: a magnetic resonance imaging analysis of screw placement relative to structures at risk. Eur Spine J 17:657-662, 2008

22. Sarwahi V, Sugarman EP, Wollowick AL, Amaral TD, Lo Y, Thornhill B: Prevalence, distribution, and surgical relevance of abnormal pedicles in spines with adolescent idiopathic scoliosis vs. no deformity: a CT-based study. J Bone Joint Surg Am 96:e92, 2014

23. Tan LA, Yerneni K, Tuchman A, Li XJ, Cerpa M, Lehman RA Jr, et al: Utilization of the 3D-printed spine model for freehand pedicle screw placement in complex spinal deformity correction. J Spine Surg 4:319-327, 2018

24. Vaccaro AR, Rizzolo SJ, Balderston RA, Allardyce TJ, Garfin SR, Dolinskas C, et al: Placement of pedicle screws in the thoracic spine. Part II: An anatomical and radiographic assessment. J Bone Joint Surg Am 77:1200-1206, 1995

25. Watanabe K, Lenke LG, Matsumoto M, Harimaya K, Kim YJ, Hensley M, et al: A novel pedicle channel classification describing osseous anatomy: how many thoracic scoliotic pedicles have cancellous channels? Spine (Phila Pa 1976) 35:1836-1842, 2010

26. Watanabe K, Matsumoto M, Tsuji T, Ishii K, Takaishi H, Nakamura M, et al: Ball tip technique for thoracic pedicle screw placement in patients with adolescent idiopathic scoliosis. J Neurosurg Spine 13:246-252, 2010

27. Zindrick MR, Wiltse LL, Doornik A, Widell EH, Knight GW, Patwardhan AG, et al: Analysis of the morphometric characteristics of the thoracic and lumbar pedicles. Spine (Phila Pa 1976) 12:160-166, 1987

\section{Disclosures}

Dr. Lenke receives research support from AOSpine, Scoliosis Research Society, EOS, and Setting Scoliosis Straight Founda- tion. Dr. Lenke is a paid consultant for and/or received royalties from Medtronic, DePuy, K2M, Quality Medical Pub. Dr. Lenke is on the editorial or governing board of Journal of Neurosurgery: Spine, Spine Deformity Journal, Spine, Scoliosis, Journal of Spinal Disorders \& Techniques, www.iscoliosis.com, www. spineuniverse.com, Backtalk (Scoliosis Association), Global Spine Outreach, and Orthopaedic Research and Education Foundation. Dr. Lenke also reports having received reimbursement for airfare/ hotel from Broadwater, the Seattle Science Foundation, Stryker Spine, and the Spinal Research Foundation; grant support from EOS; and philanthropic research funding from the Fox Family Foundation and Evans Family Donation; and serving as an expert witness in a patent infringement case for Fox Rothschild, LLC. Dr. Lehman is on the editorial or governing board of Spine Deformity, The Spine Journal, AOSpine, Cervical Spine Research Society, North American Spine Society, and Scoliosis Research Society. Dr. Lehman is a paid presenter, consultant, or speaker for DePuy, a Johnson \& Johnson Company; Medtronic; and Stryker. Dr. Lehman receives publishing royalties from Wolters Kluwer Health-Lippincott Williams \& Wilkins.

\section{Author Contributions}

Conception and design: all authors. Acquisition of data: Lin, Wei. Analysis and interpretation of data: Lenke, Lin, Wei, Shillingford, Beauchamp, Tan. Drafting the article: Lin, Wei, Lehman. Critically revising the article: all authors. Reviewed submitted version of manuscript: all authors. Statistical analysis: Lin, Shillingford. Study supervision: Lenke, Lin, Wei, Tan, Kim, Lehman.

\section{Correspondence}

Lawrence G. Lenke: The Spine Hospital, NewYork-Presbyterian/ Allen, New York, NY.112989@cumc.columbia.edu. 